\title{
Perpendicular Magnetic Anisotropy in Ni/Pt Quadrilayers
}

\author{
X. T. Gao, Y. Nagaie, H. Kawasaki*, S. Aoki**, M. Munakata**, and M. Ohkoshi \\ Faculty of Computer Science, Kyushu Institute of Technology, 680-4 Kawazu, Iizuka City, Fukuoka 820-8502, Japan \\ *Sasebo National College of Tech., 1-1 Okishin, Sasebo City, Nagasaki 857-1193, Japan \\ ** Sojo Univ., 4-22-1 Ikeda, Kumamoto City, Kumamoto 860-0082, Japan
}

\begin{abstract}
$\mathrm{Ni} / \mathrm{Pt}$ quadrilayers were deposited by excimer laser ablation in a sequence of $\mathrm{Ni} / \mathrm{Pt} / \mathrm{Ni} / \mathrm{Pt}$ and a reversed sequence of $\mathrm{Pt} / \mathrm{Ni} / \mathrm{Pt} / \mathrm{Ni}$. Perpendicular magnetization was observed in $\mathrm{Ni} / \mathrm{Pt} / \mathrm{Ni} / \mathrm{Pt}$ films, while in-plane magnetization was observed in $\mathrm{Pt} / \mathrm{Ni} / \mathrm{Pt} / \mathrm{Ni}$ films. The perpendicular magnetic anisotropy observed in $\mathrm{Ni} / \mathrm{Pt} / \mathrm{Ni} / \mathrm{Pt}$ films is ascribed to $\mathrm{Ni}_{3} \mathrm{Pt}$ generated by an interlayer mixing.
\end{abstract}

Key words: Ni-Pt, perpendicular magnetic anisotropy, multilayer, laser ablation

\section{$\mathrm{Ni} / \mathrm{Pt} 4$ 層膜における垂直磁気異方性}

\author{
高 興涛・長家慶尚・川崎仁晴*・青木振一**・宗像 誠**・大越正敏 \\ 九州工業大学・情報工学部，福岡県飯塚市川津 680-4（干 820-8502） \\ *佐世保高専, 長崎県佐世保市沖新町 1-1（于857-1193） \\ **崇城大・エネルギーエレクトロニクス研究所, 熊本県熊本市池田 4-22-1（テ860-0082）
}

\section{1. はじめに}

$\mathrm{Fe}-\mathrm{Pt}$ や $\mathrm{Co}-\mathrm{Pt}$ における $\mathrm{L}_{0}$ 型規則相は高い結晶磁気異方性を示 すことから多層膜を含め多くの研究が行われているが, Ni/Pt 多層 膜に関する研究は少ない. Ni-Pt はffc 全率固溶系であり, キュリ 一点 $T$ c はPt 濃度が増えると Ni の $353{ }^{\circ} \mathrm{C}$ から単調に減少して 30 at\% Pt 付近で室温になる ${ }^{1)}$. Krishnan 等は電子ビーム蒸着により $\mathrm{Ni} / \mathrm{Pt}$ 多層膜を作製して $5 \mathrm{~K}$ において垂直磁気異方性を見出し，高 い基板温度 $\left(200{ }^{\circ} \mathrm{C}\right)$ では垂直磁気異方性が増大して垂直磁化膜 となることを報告した ${ }^{2)}$. 界面のシャープな $\mathrm{Ni} / \mathrm{Pt}$ 多層膜では室温 においても垂直磁気異方性を生じることが知られている ${ }^{3-6)}$. 垂 直磁気異方性の原因としては主として Ni 層と Pt 層間の大きな格 子不整合 $(\sim 10 \%)$ による逆磁歪効果によると考えられるが ${ }^{4}$, MBE で作製した Ni/Pt 多層膜ではNi 層中の応力は久陥を生じることで 解放されているとの報告もある ${ }^{5}$. Ni/Pt 多層膜の磁化に関しても 議論のあるところであり，界面での合金化による磁化の減少も指 摘されている ${ }^{6)}$.

本研究ではパルス・レーザー・アブレーション法により $\mathrm{Ni} / \mathrm{Pt} / \mathrm{Ni} / \mathrm{Pt} 4$ 層膜と積層順を逆にしたPt/Ni/Pt/Ni4層膜を作製し た. ナノ秒パルス幅のレーザー・アブレーションで放出された粒 子ビームには原子, イオン, クラスタなどが含まれており運動工 ネルギーが数 $10 \mathrm{eV}$ と高いため, 低い基板温度でも結晶性の良い 薄膜を作製できることが知られている ${ }^{7)}$. 我々は $\mathrm{Co} / \mathrm{Cu}$ 多層膜を作 製して数原子層まで良好な積層構造を示すこと等を報告してきた が ${ }^{8)}$ ，レーザー・アブレーションで作製した Ni/Pt4 層膜の磁気異 方性は積層順により異なることが分かったので報告する.

\section{2. 実験方法}

波長 $248 \mathrm{~nm}$ ，パルス半值幅 $27 \mathrm{~ns}$ の $\mathrm{KrF}$ エキシマレーザーを用 いて, Ni とPtのターゲットを切り替えることにより, 真空度 $10^{-}$ ${ }^{7}$ Torr，基板温度 $200{ }^{\circ} \mathrm{C}$ におい，ガラス基板上に Pt から順に $\mathrm{Pt} / \mathrm{Ni} / \mathrm{Pt} / \mathrm{Ni}$ とした4層膜（Pt/Ni4 層膜と呼ぶ）と，Ni から順に $\mathrm{Ni} / \mathrm{Pt} / \mathrm{Ni} / \mathrm{Pt}$ とした 4 層膜（Ni/Pt4 層膜と呼ぶ）を作製した. 1 層目と 3 層目，および 2 層目と 4 層目の厚さは等しくなるように
した.レーザー・エネルギーは $300 \mathrm{~mJ}$ ，繰り返し周波数は $1 \mathrm{~Hz}$ であった. ターゲットー基板間距離は $25 \mathrm{~mm}$ である. Ni の成長速度 は $1.0 \AA / p u l s e$ であり $\mathrm{Ni}$ 層厚 $t_{\mathrm{Ni}}$ は200-1000 $\mathrm{A}$, Pt の成長速 度は $0.85 \AA /$ pulse であり, Pt層厚 $t_{\mathrm{Pt}}$ は400 $\AA$ 以下とした。

磁気特性は振動試料型磁力計を用いて室温で測定し, 結晶構造 はX線回折装置（Cu-K $\alpha$ 線）によって調べた.

\section{3. 実験結果と考察}

\section{1 磁気特性}

$\mathrm{Pt} / \mathrm{Ni} 4$ 層膜と $\mathrm{Ni} / \mathrm{Pt} 4$ 層膜の飽和磁化 $M_{s}$ を全膜厚に対す る $\mathrm{Pt}$ 層厚の割合 $t P t \%=t_{\mathrm{Pt}} /\left(t_{\mathrm{Ni}}+t_{\mathrm{Pt}}\right)$ に対して整理して Fig. 1 (a)に示す. Pt 層厚の割合 $t P t \%$ が大きくなると, $\mathrm{Pt} / \mathrm{Ni} 4$ 層膜と Ni/Pt4 層膜の $M_{\mathrm{s}}$ はほぼ単調に減少する。図 中の破線は、Ni 層と Pt 層が合金化せずにそれぞれ存在し、 Ni はバルクの飽和磁化を保っているとしたものである. $t P t \%$ の増加による $M_{\mathrm{s}}$ の減少は図中の破線より激しいので, $\mathrm{Ni}$ 層とPt 層とはかなり混ざって合金化していることが示 唆される. Ni と Pt とが層構造をとらずに完全に合金化し ているとすると, Ni と Pt の密度としてバルク值 $8.85 \mathrm{~g} / \mathrm{cm}^{3}$ と $21.37 \mathrm{~g} / \mathrm{cm}^{3}$ を用いれば, $\mathrm{Ni}_{3} \mathrm{Pt}$ 組成に対応する $\mathrm{Pt}$ 層厚 割合 $t P t \%$ は $31.5 \%$ あ゙あ。 $t P t \%=31.5 \%$ \% $/ \mathrm{Ni} 4$ 層膜 の $M_{\mathrm{s}}$ は, $\mathrm{Ni}_{3} \mathrm{Pt}$ 単層膜で報告されている值 ${ }^{9)}$ に近い. しか しながら, Fig. 1(a)からわかるようにPt層厚割合 tPt\% が 38 \% （ $T_{\mathrm{c}}$ が室温となる $30 \mathrm{at} \% \mathrm{Pt}$ に対応）以上でも室温で 磁化を保っているので，膜全体が合金化するには至ってい ないと考えられる.

Fig. 1 (b) に膜面垂直方向の保磁力 $H_{\mathrm{c} \perp}$ を Pt 層厚の割合 $t P t \%$ に対して示す. Pt/Ni4 層膜の $H_{\mathrm{c} \perp}$ は寸べて数 $100 \mathrm{e}$ であり磁化容易方向は膜面内であった。Ni/Pt4 層膜では tPt％ 30％において垂直方向の保磁力が顕著に増大し, 大きな $H_{\mathrm{c} \perp}$ を示す膜では垂直磁気異方性が誘導されている ことがわかった， $t P t \%=29$ \%の Ni/Pt4 層膜の磁化曲線を Fig. 2 に示寸．（a）は膜面内での，(b) は膜面垂直方向の磁 

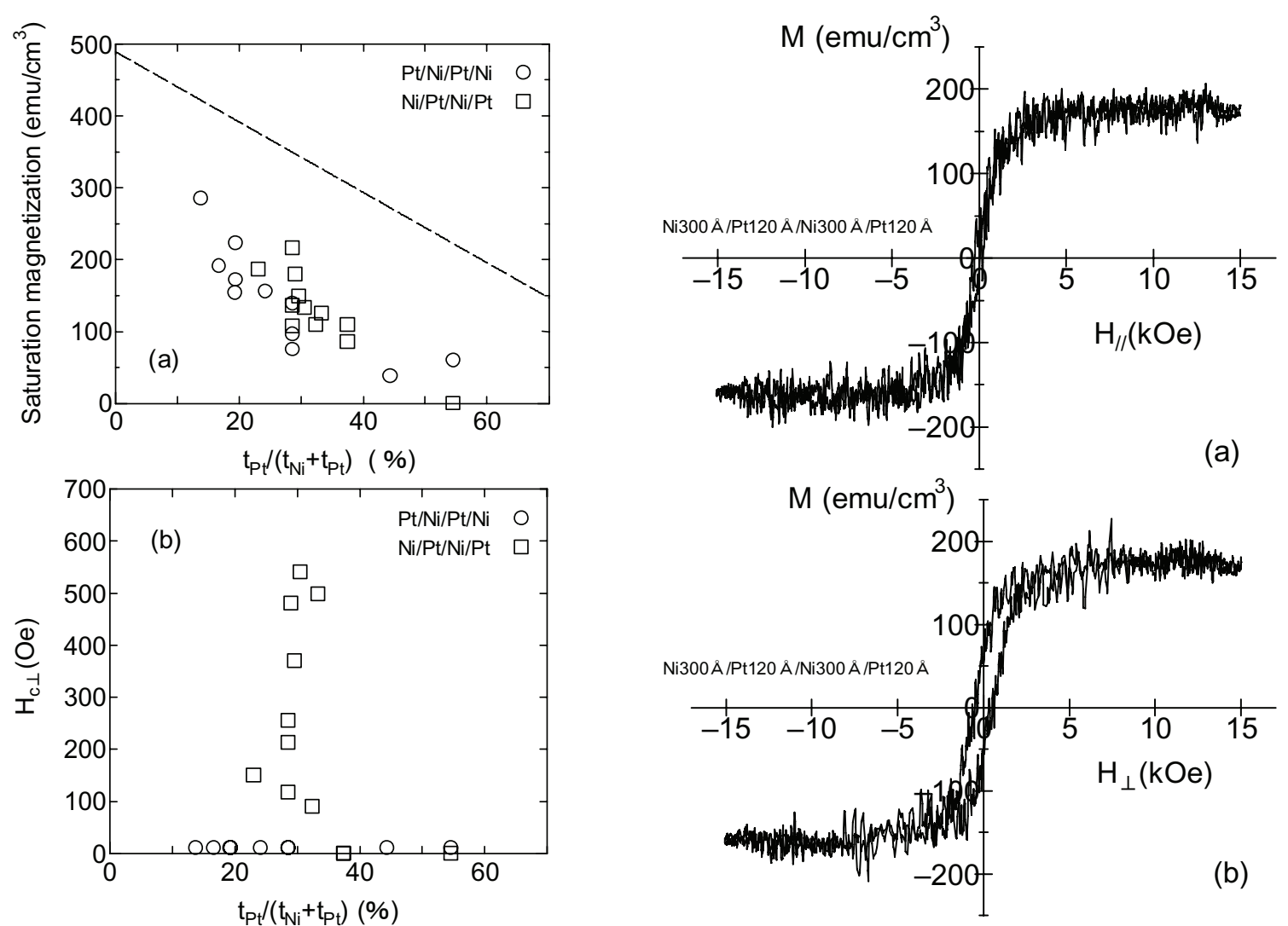

Fig. 1 Saturation magnetization $M_{\mathrm{s}}$ (a) and perpendicular coercive force $H_{c}$ (b) as functions of the Pt-layerthickness ratio $t P t \%$.

Fig. 2 Magnetization curves (a) in the film plane and (b) perpendicular to the film plane in an Ni300A/Pt120A/Ni300A/Pt120A film.

化曲線である. 膜面内では残留磁化が殆ど無いのに対して 垂直方向では残留磁化が大きく, $H_{\mathrm{c} \perp}$ は $4800 \mathrm{e}$ であった. 磁化容易方向は膜面垂直であることがわかる. 面内, 面直 の磁化曲線の面積の差から磁気異方性エネルギーを評価し た結果, 垂直磁気異方性の大きさは反磁界エネルギー $2 \pi M_{\mathrm{s}}^{2}$ を越える程度〜 $10^{5} \mathrm{erg} / \mathrm{cm}^{3}$ と見積もられる.

\section{2 膜構造}

エキシマレーザー・アブレーションで作製した Ni 単層膜は fcc (111) 配向しており格子定数はバルク值に等しく, 磁化 容易方向は膜面内であった. Pt 単層膜も f c c (111) 配向してお り格子定数はバルク值に等しかった. $\mathrm{Pt} / \mathrm{Ni} 4$ 層膜の X 線回 折パターンを Fig. 3 に示す. Pt (111) と Ni (111)のピークが認め られ, これらの面間隔は単層膜のものとほぼ等しいが, それらの 間にブロードな強いピークが存在する.このブロードなピークは $\mathrm{Ni}-\mathrm{Pt}$ 合金によるものと考えられ，Pt 層が厚いほど強度が増して 低角側にシフトする. これらの回折ピークから求めた $\mathrm{Pt}, \mathrm{Ni}$, $\mathrm{Ni}-\mathrm{Pt}$ の格子定数を, 全膜厚に対寸る Pt 層厚の割合 $t P t \%$ に 対して Fig.4 に示す. Pt と Ni はバルクの格子定数を保ったまま 残っているが， Ni-Pt の格子定数は $t P t \%$ とともに大きくな る. バルクの格子定数を保っている Pt と Ni はおのおの 1 層目の Pt、4 層目の Ni によるものと考えられる. 2 層目の Ni と 3 層目の

Pt は混ざってNi-Pt 合金となり， tPt％とともにPt 濃度が増えて 格子定数が大きくなる. すなわち, Ni 上のPt は相互拡散しやすい とすれば説明できる. Pt/Ni 4 層膜の磁化容易方向はすべて膜 面内であった。

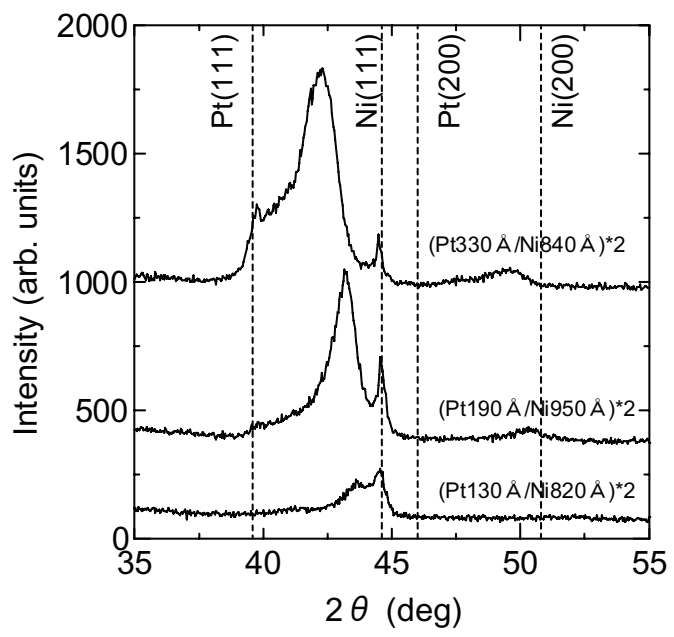

Fig. 3 X-ray diffraction patterns of $\mathrm{Pt} / \mathrm{Ni}$ 4-layers. 


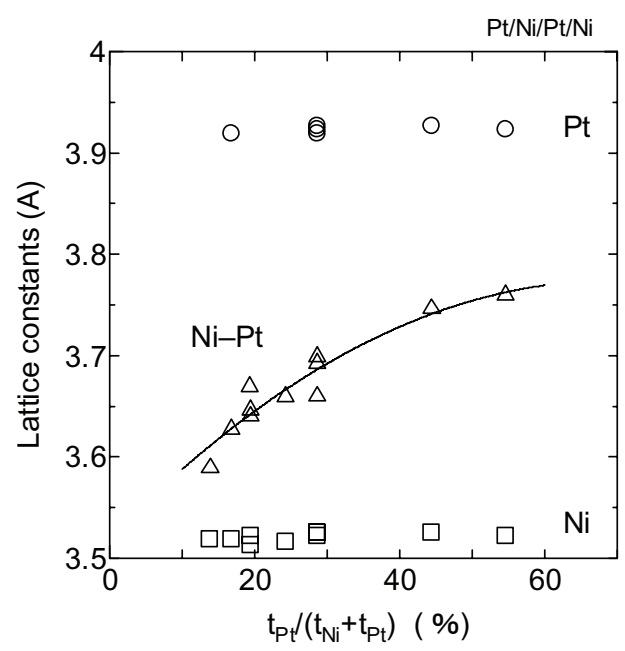

Fig. 4 Lattice constants of $\mathrm{Pt}(\bigcirc), \mathrm{Ni}(\square)$, and $\mathrm{Ni}-\mathrm{Pt}(\triangle)$ in $\mathrm{Pt} / \mathrm{Ni}$ 4-layers as functions of the Pt-layer-thickness ratio $t P t \%$. The line shown is a guide to the eye.

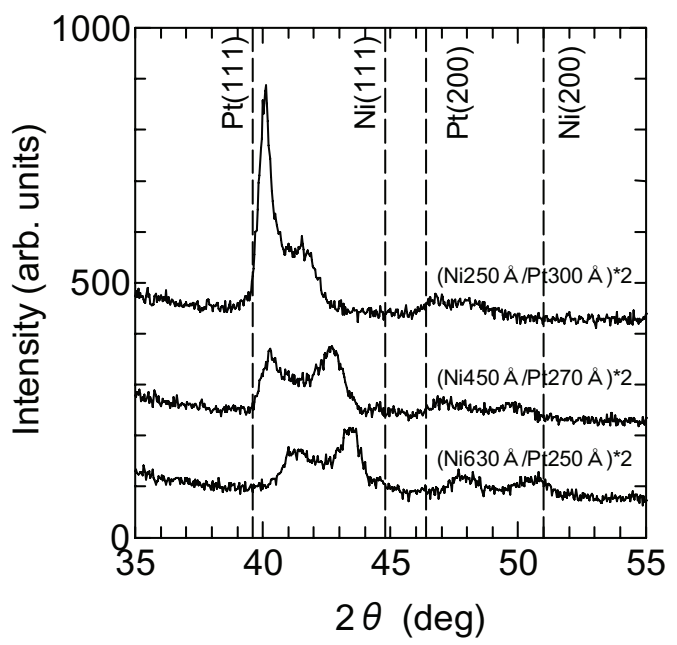

Fig. 5 X-ray diffraction patterns in Ni/Pt 4-layers.

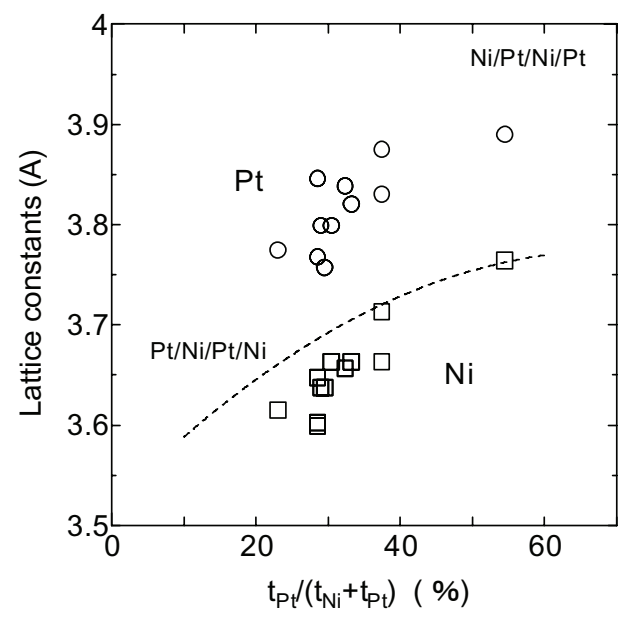

Fig. 6 Dependence of the lattice constants of $\mathrm{Pt}(\bigcirc)$ and $\mathrm{Ni}$ $(\square)$ on the Pt-layer-thickness ratio $t P t \%$ in $\mathrm{Ni} / \mathrm{Pt}$ 4-layers.
$\mathrm{Ni} / \mathrm{Pt} 4$ 層膜の X 線回折パターンを Fig. 5 に示す.Pt (111) ピークはPt層厚の割合 $t P t \%$ が小さくなると高角側にシフ トして強度が小さくなる. Ni(111) ピークは tPt\% が大き くなると低角側にシフトし，Ni の格子定数が大きくなる. $\mathrm{Ni}$ と Pt の格子定数を $t P t \%$ に対して Fig. 6 に示寸. 図中の 破線は Pt/Ni4 層膜における Ni-Pt の格子定数（Fig. 4 の実 線) である. Ni 格子定数の増加は, 1 層目の Ni に 2 層目の $\mathrm{Pt}$ が合金化し， 3 層目の Ni に 4 層目の Pt が合金化しため と考えられる.この合金化により Pt 格子定数も減少すると 考えられる，磁化容易方向が膜面垂直となるのは $t P t \%$ $30 \%$ Ni/Pt4 層膜であり, Ptの格子定数が〜3.80 Aまで 縮み, Ni の格子定数が〜3. 65 Aに伸びた場合であった。

\section{3 垂直磁気異方性亡膜構造}

垂直方向保磁力 $H_{\mathrm{c} \perp}$ と格子定数との関係を Fig. 7 に示す. $\mathrm{Ni} / \mathrm{Pt} 4$ 層膜における $H_{\mathrm{c} \perp}$ と Pt の格子定数との関係を $\square$ で, $\mathrm{Ni}$ の格子定数との関係をロで示した. Ni/Pt 4 層膜におい て垂直方向保磁力が大きくなり垂直方向が磁化容易となる のは, Pt の格子定数が $3.80 \AA$ 付近, Ni の格子定数が 3.65 A付近であることがわかる. Pt/Ni 4 層膜における $H_{\mathrm{c} \perp}$ と Pt, $\mathrm{Ni}, \mathrm{Ni}-\mathrm{Pt}$ の格子定数との関係は○で示したが, Pt/Ni 4 層 膜の保磁力は寸べて数 $100 \mathrm{e}$ であった.

$\mathrm{Ni}-\mathrm{Pt}$ 合金において格子定数が $3.80 \AA$ になる組成は 60 at\% Pt 付近であり，3.65Aになるのは $25 \mathrm{at} \% \mathrm{Pt}$ 付近，す なわち $\mathrm{Ni}_{3} \mathrm{Pt}$ である ${ }^{10)}$. エピタキシャル (111) $\mathrm{Ni}_{3} \mathrm{Pt}$ 薄膜に おいて, 成長誘導による垂直磁気異方性 (室温において 1.3 x $\left.10^{6} \mathrm{erg} / \mathrm{cm}^{3}\right)$ が報告されているので ${ }^{9)}, \mathrm{Ni} / \mathrm{Pt} 4$ 層膜にお ける垂直磁気異方性は $\mathrm{Ni}_{3} \mathrm{Pt}$ により生じていると考えられ る。

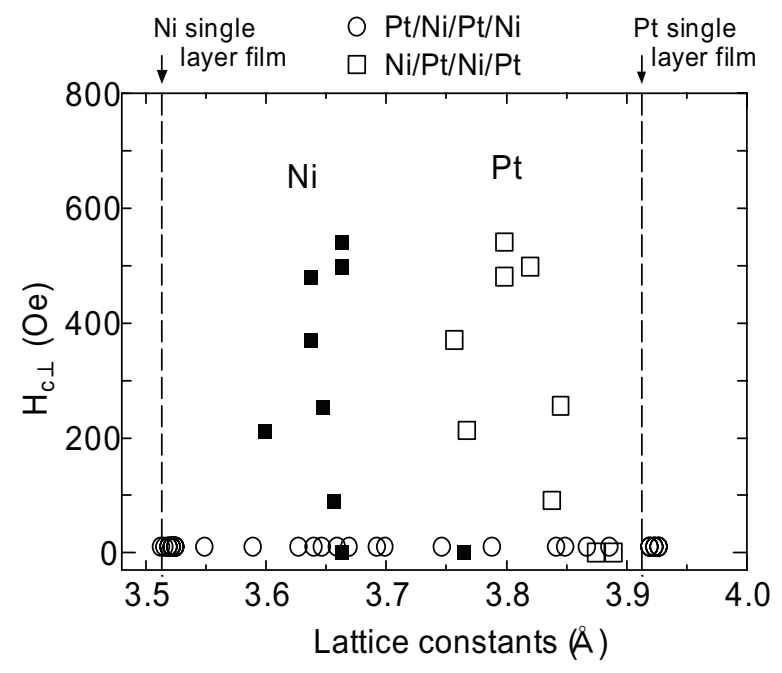

Fig. 7 Relation between the perpendicular coercive force $H_{\mathrm{c} \perp}$ and lattice constants of $\mathrm{Ni}, \mathrm{Pt}$, and $\mathrm{Ni}-\mathrm{Pt}$. $\square: \mathrm{Pt}, \square: \mathrm{Ni}$ in Ni/Pt 4-layers.

$\mathrm{O}: \mathrm{Pt}, \mathrm{Ni}$, and $\mathrm{Ni}-\mathrm{Pt}$ in $\mathrm{Pt} / \mathrm{Ni}$ 4-layers. 
Ni と Pt の膜厚方向分布をXPS で評価した結果，合金化 の進んでいることは判明しているが, 詳細な検討は今後の 研究課題である. NiO 等の酸化物の存在は X 線回折からも 確認されていないが, 垂直磁気異方性と膜構造との関係を より明らかにする必要がある.

\section{4. まとめ}

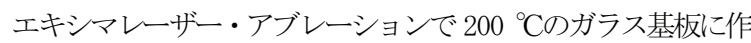
製したPt/Ni/Pt/Ni4 層膜の磁化容易方向は膜面内であり, 2 層目の Ni と 3 層目の Pt は混ざって Ni-Pt 合金になっていると考 えられる. 積層順が逆の $\mathrm{Ni} / \mathrm{Pt} / \mathrm{Ni} / \mathrm{Pt} 4$ 層膜においては 1 層 目の Ni に 2 層目の Pt が合金化し， 3 層目の Niに 4 層目の $\mathrm{Pt}$ が合金化すると考えられる．膜厚に対する Pt 層厚の割 合が $30 \%$ 付近の $\mathrm{Ni} / \mathrm{Pt} / \mathrm{Ni} / \mathrm{Pt} 4$ 層膜では $\mathrm{Ni}_{3} \mathrm{Pt}$ を生じて垂 直磁気異方性が誘導され, 膜面垂直方向が磁化容易になっ て大きな垂直方向保磁力を示す.

\section{References}

1) R. M. Bozorth: Ferromagnetism, p.414 (Nostrand Co., Princeton, 1978).

2) R. Krishnan, H. Lassri, S. Prasad, M. Porte, and M. Tessier,: J. Appl. Phys. 73, 6433 (1993).

3) F. Wilhelm, P. Poulopoulos, G. Ceballos, H. Wende, and K. Baberschke, P. Srivastava, D. Benea, H. Ebert, M. Angelakeris, N. K. Flevaris, D. Niarchos, A. Rogalev, and N. B. Brookes: Phys. Rev. Lett. 85, 413 (2000).

4) Young-Soek Kim, Sung-Chul Shin: Phys. Rev. B, 59, R6597 (1999)

5) W. Staiger, A. Michel, V. Pierron-Bohnes, N. Hermann, and M. C. Cadeville: J. Mater. Res., 12, 161 (1997).

6) P. Poulopoulos, F. Wihelm, H. Wende, G. Ceballos, K. Baberschke, D Benea, H. Ebert, M. Angelakeris, N. K. Flevaris, A. Rogalev, and N. Brookes: J. Appl. Phys., 89, 3874 (2001).

7) P. R. Willmott: Prog. Surf. Sci. 76, 163 (2004).

8) K. Tagashira, A. Sakaue, S. Tomoeda, H. Ohtao, and M. Ohkoshi : $J$. Magn. Soc. Jpn., 23, 1253 (1999).

9) D. Vasumathi, A. L. Shapiro, B. B. Maranville, F. Hellman: J. Magn. Magn. Mater, 223, 221 (2001).

10) U. Kumar, K. G. Padmalenkha, P. K. Mukhopadhyay, D. Paudyal, and A. Mookerjee: J. Magn. Magn. Mater., 292, 234 (2005).

2006 年 10 月 9 日受理, 2006 年 12 月 7 日再受理, 2007 年 1 月 23 日採

\section{録}

